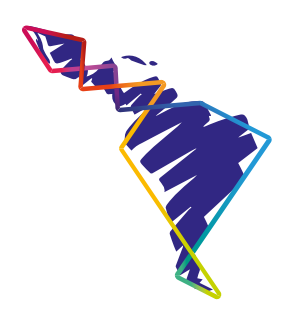

\title{
Financiación en materia de educación como derecho humano
}

\author{
Financing in Education as a human \\ right
}

\section{Financiamento da educação como direito humano}

\author{
Yesenia del Carmen Trejo Cruz ${ }^{1}$
}

\begin{abstract}
Resumen
Los derechos humanos en México, a la luz de su incursión en el sistema constitucional en el 2011, desdoblan su aplicación en todos los ámbitos normativos, como aspecto que mejora las condiciones de vida de los mexicanos, al igual que el educativo, el cual, simultáneamente, se configura como instrumento que garantiza su cumplimiento. Dichas prerrogativas establecen un paradigma, a modo de nuevo orden jurídico, que impone a las autoridades el deber de acatarlas en sus respectivas funciones. En este contexto, la educación como garantía se analiza con base en las fuentes de financiamiento otorgadas por los entes públicos, que encaran periódicamente, en sus competencias gubernamentales, la determinación del presupuesto que solvente y garantice su puesta en práctica en territorio nacional. Subyacen, al mismo tiempo, los límites impuestos a las partidas, fundamentados en la justificación del interés colectivo, ratificado por la Suprema Corte de Justicia de la Nación. En este orden de ideas, señalamos como objetivo de la investigación precisar la solvencia presupuestal otorgada a la educación como un derecho humano.
\end{abstract}

Palabras clave: financiación, educación, programas, derecho humano, desarrollo.

Recibido: 16-8-2019 - Aceptado: 25-11-2021

1 Docente de la Facultad de Derecho e investigadora de tiempo completo en el Instituto de Investigaciones Jurídicas de la Universidad Veracruzana, Xalapa-México. Posdoctora en Derecho Tributario Europeo y especialista en Gestión Tributaria por la Universidad de Castilla-La Mancha, Toledo, España. Doctora y licenciada en Derecho por la Universidad Veracruzana; nivel I en el Sistema Nacional de Investigadores; integrante del Colegio Nacional de Profesores e Investigadores en Derecho Fiscal y Finanzas Públicas, A.C. Participa del proyecto "Sostenibilidad ambiental dentro de las estrategias de economía circular: propuestas sobre instrumentos financieros y tributarios", en la Universidad de Castilla-La Mancha, Toledo, España. Correo electrónico: maestriaderecho@hotmail.com, (D) https://orcid.org/0000-0002-9642-1189 


\begin{abstract}
Human rights in Mexico, in light of its incursion in the constitutional system in 2011, unfold their application in all normative areas, as a condition that improves the living conditions of Mexicans; including the educational sector, which at the same time is configured as an instrument that guarantees its fulfillment. These prerogatives establish a paradigm, as a new legal order, that imposes on the authorities the duty to abide by them in their respective functions. In this context, education as a guarantee is analyzed based on the sources of financing granted by public entities, which periodically face in their governmental competences, the determination of the budget that solves and guarantees its application in the national territory. At the same time, it underlies the limits that are imposed on budget allocations, based on the justification of the collective interest, ratified by the Supreme Court of Justice of the Nation. In this order of ideas, we indicate as an objective of the investigation, to specify the budgetary solvency granted to education as a Human Right.
\end{abstract}

Keywords: Financing; Education; Programs; Human Right; Development.

\title{
Resumo
}

Direitos humanos no México, à luz de sua incursão no sistema constitucional em 2011, desdobra sua aplicação em todas as áreas normativas, como uma condição que melhora as condições de vida dos mexicanos; assim como o educacional, que ao mesmo tempo se configura como um instrumento que garante sua realização. Essas prerrogativas estabelecem um paradigma, como uma nova ordem jurídica, que impõe às autoridades o dever de cumpri-las em suas respectivas funções. Neste contexto, a educação como garantia é analisada com base nas fontes de financiamento concedidas pelos entes públicos, que enfrentam periodicamente nas suas competências governamentais, a determinação do orçamento que resolve e garante a sua aplicação no território nacional. Ao mesmo tempo, está subjacente aos limites que se impõem aos jogos, com base na justificação do interesse coletivo, homologada pelo Supremo Tribunal de Justiça da Nação. Nessa ordem de ideias, indicamos como objetivo da investigação, especificar a solvência orçamentária conferida à educação como direito humano.

Palavras-chave: Financiamento; Educação; Programas; Direitos humanos; Desenvolvimento.

\section{Introducción}

La investigación que se presenta tiene como antecedente la introducción de los derechos humanos al sistema constitucional de México —en el 2011—, reforma política y modernista que estatuye, en todo el país, el deber de los entes públicos de garantizarlos en sus respectivos ámbitos competenciales, a favor de todos los ciudadanos. De este modo, se acoge la educación como instrumento para la realización de esos derechos, los cuales ponen de manifiesto un parteaguas, en la interrelación existente entre gobernantes y gobernados, ante la regulación normativa constitucional y legislativa que actualmente les atribuye el Estado mexicano, cuyo 
respeto irrestricto se fundamenta, al mismo tiempo, en la financiación otorgada para su desarrollo en el territorio nacional.

Reconocemos que se trata de un tema polémico y vulnerable, el cual involucra aristas múltiples, en razón de la trascendencia que representan el conocimiento y avance científico en la sociedad.

Nuestra línea por seguir en este objeto de estudio remite a las partidas que, con base en las contribuciones federales, anualmente se destinan para sostener, en la praxis, la función estatal, en atención al derecho social que representan. Se alude, por lo tanto, al objetivo en este aporte científico, en precisar si las partidas presupuestales dan financiamiento a la educación en su condición como derecho humano.

El avance de una sociedad se atribuye, principalmente, a su grado de conocimiento, como base para el progreso; a obtener mejores condiciones de vida, en la población que ha recibido su formación básica a superior, como elementos para la adquisición de bienes y desenvolvimiento personal.

La educación, por lo tanto, aporta los límites o rompe las fronteras en los individuos, como depositarios de actividades y funciones que puedan incidirle al ser parte de la comunidad.

Los presupuestos que conciban el solvento a los programas educativos serán analizados cuantitativamente, en la suficiencia de su aportación, ratificada en la postura jurisprudencial del Máximo Tribunal Judicial, la Suprema Corte de Justicia.

Al gasto público en materia educativa, a la luz del criterio jurisprudencial, se le imponen límites por los entes públicos estatales - legislativo y ejecutivo-, como derecho humano en México; esto con base en sus encomiendas constitucionales, relativas a la presentación y aprobación de iniciativas de los ejercicios fiscales.

Abordamos, por ende, la temática señalada, en alcance a la regulación que jurídicamente se hace de este derecho, en la prelativa constitucional, legal y administrativa. Acto seguido, identificamos las partidas económicas que, con fuente en tributos, sostienen los programas educativos, los cuales por su carácter obligatorio el Estado debe proporcionar en niveles y territorios de México.

El estudio en mención, en su corte deductivo, involucra la implementación de métodos de conocimiento, como el descriptivo, analítico, sistemático y propositivo, los cuales permiten desarrollar los tópicos que sostienen nuestro objeto de estudio, de cara a las fuentes de financiación promotoras del cumplimiento de la educación como derecho humano. Por otra parte, para evidenciar las hipótesis 
formuladas, acudimos al empleo del método cuantitativo; este nos conduce a la precisión numérica de las partidas presupuestales, otorgadas a los segmentos que remiten al ejercicio de la educación garante del derecho humano.

Cabe mencionar que esta indagación es un producto científico, derivado de la estancia académica realizada en la Universidad Federal de Pernambuco, Facultad de Derecho Estatal, y en la Universidad de Caruaru, Recife, al noreste de Brasil -2017-, en coordinación con la Universidad Veracruzana, México. Lo anterior con la finalidad de fomentar, difundir y socializar, en docencia e investigación, el financiamiento de la educación como un derecho humano, en ámbitos educativos de la Licenciatura en Derecho, Educación y el Postgrado en Derechos Humanos. Esto trajo como resultados: la retroalimentación en planes y programas de estudios; la determinación social de la política educativa y fiscal; la difusión transversal de las finanzas públicas en su incidencia social; la comparación y aplicación pragmática de la educación, así como la ratificación de los derechos humanos en su cumplimiento.

\section{Regulación de la educación como derecho humano}

La educación como objeto de estudio requiere ser abordada desde una visión constitucional y dogmática, que permita desarrollar sus fines como derecho humano, a la luz de los objetivos del Plan de Desarrollo 2013-2018, como encargado de regular las actividades que en el nivel nacional y por medio de programas se han de realizar en el territorio mexicano.

Atentos a una prelación normativa, la Constitución encabeza el grupo de ordenamientos que disponen el tratamiento de la educación a favor del particular, como derecho social y, por ende, humano. Este normativo supremo recoge el grupo de garantías que en su capítulo I destina al cumplimiento de garantías y derechos humanos.

Es menester expresar que la evolución de nuestros textos constitucionales ha sido marcada por el devenir histórico, económico y social, que representa el contexto y las demandas por atender ante la población, desde un México independiente a hoy: 1824, 1836, 1843, 1857 y 1917. Estas fechas identifican la vigencia de la normativa constitucional, como referente al reconocimiento y respeto de los derechos humanos, con antelación garantías individuales.

México, en su vida constitucional, obedece a los cambios que, como país democrático, se introducen en respuesta a la génesis de un Estado de derecho-constitucional. De tal condición emana el estudio pragmático y legislativo de estas premisas, que dieron vida a una entidad regulada con bases jurídicas, sociales y garantistas, orientadas a mejorar el nivel de vida de sus destinatarios. 
Significamos también que estos aportes, en nuestro texto constitucional vigente, establecen características a una nación que busca la aplicación de nuevas instituciones, ante la protección de los ámbitos jurídicos y económicos de los particulares.

Para cualquier estudio inmerso o con vinculación a estos tópicos en mención, debemos significar dichos aportes, en la construcción de sistemas conducentes a la creación de un Estado. Este último se vislumbra fincado en ámbitos legales y garantistas que atiendan sus funciones hacia un bien común.

No es el objetivo de la presente investigación profundizar en la génesis y el desenvolvimiento de las garantías en México, pero sí remitimos al texto que nos rige hoy - desde su creación a una vida contemporánea-. La aplicación de las garantías se ha observado fundamentada en los numerales del 1 al 29 (Constitución Política de los Estados Unidos Mexicanos, CPEUM, 2016), en un sentido estricto - título I, capítulo I- en la defensa de los particulares que han sido vulnerados en sus ámbitos, por medio de actos y procedimientos de autoridad, sin corresponder a una tutela distinta ante la terminología sobre derechos humanos.

En estas ideas, los agraviados que han necesitado el auxilio e intervención del Poder Judicial, frente a un resolutivo o determinación que les afecte, se han cimentado en esos preceptos, para invocar el reconocimiento a sus derechos fundamentales, atentos a la mención que nuestra Carta Magna atribuye, como inherentes y previos a su creación.

Se destaca así una postura iusnaturalista — ante la positivista—, que se caracteriza por determinar funciones y actos de los entes públicos, con apego a la persona y sus derechos, sin necesidad de su establecimiento o gestación a letra de ley, es decir, no se requiere que el Estado los regule como tales; en otras palabras: se hacen inherentes a la existencia de este grupo de prerrogativas, que al ser humano le corresponden por el hecho de vivir.

Ante esta visión centrada en el individuo, todos gozamos del amparo que el Estado recoge de esos derechos preconcebidos, en leyes y Constitución, este no los atribuye u otorga, en razón lógica de ser un ente colectivo; aquel es creado por la comunidad que le ha dado vida, para una mejor organización social.

Por antonomasia, tal ideología acopia un tratamiento digno y equitativo para las personas, en relación con su convivencia entre ellas y órganos públicos. Aludimos, en especial, a la corriente de pensamiento apoyada en un iusnaturalismo racionalista del siglo XVIII, que advertía colocar a la población en un margen de respeto y reconocimiento a ella misma, ante el quehacer de autoridades; Zipellius 
(1985, p.42) menciona que "si los hombres viven fuera de un orden comunitario justo, degeneran".

Barroso (2008, p.50) es muy preciso en decir que "con independencia a la divinidad y enfoque de la naturaleza, esta corriente apuntada, destaca la reingeniería estatal de algunos países, como es el caso de Brasil y México". Para este investigador, tal ideología se fundamenta en la reforma fechada el 10 de junio de 2011; a la luz de su introducción en el texto constitucional, el artículo $1^{\circ}$ dispone la tutela de los derechos humanos, a través de los actos de toda autoridad en México, en sus ámbitos respectivos, vía las garantías reguladas en su título I supra-.

Con esa adición constitucional, México se pone a la vanguardia en defender, garantizar y cumplir los derechos en beneficio de los particulares, como prescribir su protección en tratados internacionales, leyes y principios de universalidad, interdependencia, indivisibilidad y progresividad aplicables. "En este punto se supera la idea restrictiva de vinculación positiva del administrador a la ley, en la lectura convencional del principio de la legalidad, por el cual su actuación estaba basada por aquello que el legislador hubiera determinado o autorizado" (Barroso, 2008, pp. 50-51).

Este panorama proteccionista y extranacional de los derechos humanos da origen a un parteaguas: la renovación del Estado de derecho, que busca asistir al individuo - ahora denominado persona en esta obligatoriedad como ente público frente a la colectividad-, en los casos que el deber así lo amerite.

Los estudios constitucionales, por lo tanto, han tomado un nuevo auge, los procesos jurisdiccionales también reciben estos aportes, así como los pronunciamientos del máximo Tribunal Judicial, ante la solicitud de los justiciables por violaciones a sus derechos y garantías fundamentales.

La constitucionalización, [...], expresa la irradiación de los valores constitucionales por el sistema jurídico. Esa difusión de la ley mayor por el ordenamiento ocurre por la vía de la jurisdicción constitucional, que contiene la aplicación directa de la Constitución a determinadas cuestiones [...] (Barroso, 2008, p. 56).

No concebimos un cambio trascendental bajo una nueva terminología. Dejar de ser garantías para ahora ser llamadas derechos humanos no es el conducto para gozar de un derecho pleno como ciudadano; se trata, entonces, de potencializar y convertir en eficientes las instituciones, leyes y funciones de los entes en su totalidad, para aplicar en la ciudadanía sus derechos preconcebidos. Lo anterior, con 
independencia a las variantes y responsabilidad explícita que advierte esta reforma, como un antes y un después en los derechos inherentes a la persona. Esto no significa un desacierto a la reforma, con antelación se han pronunciado resolutivos que se adecuan a tales condicionantes constitucionales y otros que han requerido de la intervención del Poder Judicial en su instancia última, para tal reconocimiento de garantías o derechos humanos.

De esta forma, las autoridades siempre han quedado en los márgenes normativos ante cumplimiento y resguardo de premisas legislativas y constitucionales, que figuran como diques a su actuación, en excesos u omisiones, los cuales representen violación a la gama de libertades individuales:

El administrador puede y debe actuar teniendo por fundamento directo la Constitución y, en muchos casos, independientemente de cualquier manifestación del legislador ordinario. El principio de la legalidad cambia, de esta forma, para el principio de la constitucionalidad o, quizá más propiamente para el principio de la juridicidad, comprendiendo su subordinación a la Constitución y a la ley, en este orden (Barroso, 2008, pp. 50-51).

Dicho en otras palabras, la reforma viene a destacar esta función no desconocida para los entes públicos; sí asevera su grado de responsabilidad en sus atribuciones y desarrollo como órganos que realizan atribuciones del Estado para el bien colectivo.

Por ende, atento a la teleología del Estado, Trejo (2006) dice que "[...] la justificación del Estado se apoya en el desarrollo de la personalidad del ser humano; [...]" (p. 75); esta reforma pone hincapié al pregón que argumenta su existencia: la búsqueda del bien común. El aspecto sustantivo previo rige la vida de toda comunidad estatal bajo una teoría política, en el afán de servir y lograr el beneficio de la población, no solo su propio bienestar.

De este modo, la educación en derechos humanos debe abarcar las cuestiones relativas a la educación formal; la escuela; los procedimientos pedagógicos; las agendas e instrumentos que posibiliten una acción pedagógica de creación de conciencia y liberadora, orientada hacia el respeto y valoración de la diversidad; y, los conceptos de sostenibilidad y de formación de la ciudadanía activa (Comité Nacional, 2008, p. 51).

Acto seguido, nos identificamos con la corriente iusnaturalista del siglo XVIII, sin demeritar los ideales de cambio de los estados democráticos y neoliberales; pero es latente la necesidad de apoyo y fundamento en las ideologías que marcan un proceso de integración y realización estatal, sin detrimento del ser humano. Tales 
aspectos se merman en la aplicación actual de naciones impregnadas de globalización y consumismo capitalista, que no han dado respuesta a las necesidades de grupo ni generan un progreso equitativo en las distintas regiones de la sociedad. Más bien, se antepone la libertad de competencia económica en la adquisición de bienes y servicios, en relaciones de particulares propias de los ámbitos nacional y extranjero.

Estos elementos -últimos - mencionados han provocado una crisis en los sistemas jurídico y económico, bajo la intervención disminuida del Estado y el dejar hacer de la sociedad civil. Es decir, el Estado paternalista modifica sus funciones como rector económico en el mercado — para México a partir de 1984-, con base en la apertura económica internacional, incidente en los otros órdenes y contextos sociales.

Tales parámetros económicos y neoliberales dan margen a la adecuación de leyes e instituciones, en aras de regular la interrelación que surge entre el Estado y grupos de particulares nacionales o no; la naturaleza proteccionista de este se ha visto decrecida, en la posibilidad de brindar los mínimos garantistas a favor del ciudadano, frente a las incursiones económicas y trasnacionales en el país.

La persona es una premisa no negociable. Ante los impactos económicos y el déficit del sistema en general, devienen efectos en la falta de cumplimiento a los objetivos públicos: dotar a una población de bienes y servicios que les conduzca en su grupo o región, asertivamente, a recintos laborales, educativos y de salud, por ejemplo.

Las líneas expresadas hasta aquí no representan la totalidad en apuntamientos que descienden de estas disciplinas abordadas, de cara a los derechos humanos y al desdoblamiento en la educación; sintetizamos, groso modo y en atención al objeto abordado, prerrogativas que permitan sostener las bases jurídicas y constitucionales, en la financiación efectuada por la política fiscal mexicana, en el periodo 2017-2018.

Nos adentramos, de esta manera, en el estudio de los instrumentos legales que nos permitan el tratamiento de nuestros planteamientos:

\section{a) Constitución}

A continuación, transcribimos el párrafo $3 .^{\circ}$ del artículo $1 .^{\circ}$ de la Constitución de 1917, en su aspecto medular dedicado al reconocimiento y cumplimiento de los derechos humanos, por las autoridades mexicanas.

DE LOS DERECHOS HUMANOS Y SUS GARANTIAS. ARTÍCULO $1 \ldots$ Todas las autoridades, en el ámbito de sus competencias, tienen la obligación de promover, respetar, proteger y garantizar los derechos humanos [...] el Estado deberá 
prevenir, investigar, sancionar y reparar las violaciones a los derechos humanos, en los términos que establezca la ley (CPEUM, 2016, p. 14).

Acotado nuestro tema en el catálogo de garantías, ubicamos en el numeral 3. ${ }^{\circ}$ del texto citado el modo con el que se regula la educación como un bien al servicio del ciudadano.

[...] Para identificar cuáles son los derechos fundamentales (tanto los de contenido negativo, que implican un no hacer por parte del Estado, comúnmente llamamos libertades; como los de contenido positivo, que implican un hacer o un dar algo por parte del Estado), hay que distinguir entre el conjunto de normas que constituyen el régimen constitucional aplicable a la educación, que incluye normas relativas al ejercicio de la soberanía, a la distribución de competencias entre la Federación y los Estados, a las garantías individuales, etcétera (Barragán, 1996, p. 296).

Partiendo del precepto constitucional referido, hacemos la justificación a nuestro tópico, en alusión al contenido de su párrafo $1 .^{\circ}$, en la condición de indicar las bases de este derecho a favor de la población; igualmente, para parafrasear con posterioridad los razonamientos económicos que apoquinan impartir la educación como derecho humano en México.

Artículo 3. Toda persona tiene derecho a recibir educación. El Estado Federación, Estados, Ciudad de México y Municipios, impartirá educación preescolar, primaria, secundaria y media superior. La educación preescolar, primaria y secundaria conforman la educación básica; ésta y la media superior serán obligatorias (CPEUM, 2016, p. 18).

b) Tratados internacionales

En materia de instrumentos internacionales, México forma parte de ellos, por medio de acuerdos o convenios establecidos en los paneles que se generen en atención al tratamiento de la persona en sus derechos humanos, ante su progreso con las autoridades. De este modo, encontramos la existencia de 11 documentos de carácter general, que versan sobre los derechos humanos, esos que la nación mexicana introduce a su sistema normativo a partir de 1949.

Sobre este orden y para atender lineamientos más específicos en la defensa y protección a la persona, se adscribe México a tales acuerdos externos en rubros como derecho humanitario, desaparición forzada, personas con discapacidad, esclavitud, genocidio, medio ambiente, migración, menores de edad y salud (incluyendo educación y cultura). En total, suman 170 convenios signados para aplicarse en paralelo a la producción legislativa y normas fundamentales en el país. 


\section{Tabla 1}

Convenios que agrupan el cumplimiento de los derechos humanos en México

\begin{tabular}{|l|l|}
\hline De carácter general \\
\hline Nombre & Publicación en el DOF \\
\hline Carta de Organización de los Estados Americanos & $13 / 1 / 1949$ \\
\hline Carta de la Naciones Unidas & $9 / 10 / 1946$ \\
\hline Convención Americana sobre Derechos Humanos & $7 / 5 / 1981$ \\
\hline $\begin{array}{l}\text { Convención de Viena sobre el Derecho de los Tratados, } \\
\text { hecha en Viena el 23 de mayo de 1969 }\end{array}$ & $14 / 2 / 1975$ \\
\hline Convención sobre el Estatuto de los Apátridas & $25 / 8 / 2000$ \\
\hline Estatuto de la Corte Internacional de Justicia & $9 / 10 / 1946$ \\
\hline Pacto Internacional de Derechos Civiles y Políticos & $20 / 5 / 1981$ F. de E. 22/6/1981 \\
\hline $\begin{array}{l}\text { Pacto Internacional de Derechos Económicos, Sociales } \\
\text { y Culturales }\end{array}$ & $12 / 5 / 1981$ \\
\hline $\begin{array}{l}\text { Protocolo Adicional a la Convención Americana } \\
\text { sobre Derechos Humanos en materia de Derechos } \\
\text { Económicos, Sociales y Culturales }\end{array}$ & $1 / 9 / 1998$ \\
\hline
\end{tabular}

Nota. SCJN (2014, p. 19).

En el tema que se presenta, de acuerdo con su objeto de estudio mencionado, que vincula la financiación como conducto al respeto de la educación como derecho humano, se advierte la existencia de pactos internacionales que comprenden esa tónica; esto en beneficio de los receptores de la educación, a través de su admisión por la técnica legislativa y jurisprudencial (SCJN, 2014, p.22).

\section{Tabla 2}

\section{Educación y cultura}

\begin{tabular}{|l|l|}
\hline Educación y cultura \\
\hline Nombre & Publicación en el DOF \\
\hline $\begin{array}{l}\text { Convención sobre la Orientación Pacífica de la } \\
\text { Enseñanza }\end{array}$ & $17 / 6 / 1938$ \\
\hline $\begin{array}{l}\text { Convención sobre la Protección y Promoción de la } \\
\text { Diversidad de las Expresiones Culturales }\end{array}$ & $26 / 2 / 2007$ \\
\hline
\end{tabular}

Nota. $\operatorname{SCJN}(2014$, p. 22).

Así, se observa la correlación de normas en un derecho interno con fuentes internacionales, en busca de cumplir y acatar los mandamientos constitucionales, para fortalecer el Estado de derecho constitucional, cuya ratificación obedece a la reforma introducida el 10 de junio del 2011. 
Se alude, en este orden, al rediseño que el Estado hace en materia de derechos humanos, a la luz de aportes universales diversos, que conduzcan hacia la observancia de los derechos humanos a favor de los mexicanos. Regladamente, el texto constitucional acoge los postulados sobre estos derechos, por medio de su reforma introducida en el 2011, como sujeto de encomiendas supranacionales.

Se incorpora, así, a nuestro texto Constitucional, el principio pro persona o pro homine, principio que, como su nombre lo indica, y sustentado en la Tesis I.4 $4^{\circ}$.A.464 A, (2005) tiene como criterio rector el de mayor beneficio o protección para el ser humano, y que ha sido conceptuado por los tribunales de la Federación como el criterio o directriz hermenéutica [...] (Tesis I.4 ${ }^{\circ}$.A.441 A, 2004, p.1).

Para garantizar en mejor proporción, los derechos constitucionales reconocidos para los mexicanos, el criterio jurisprudencial advierte a la persona como eje, según la adición referida:

consiste en ponderar ante todo la fundamentalidad de los derechos humanos, a efecto de estar siempre a favor del hombre, lo que implica que debe acudirse a la norma más amplia o a la interpretación extensiva cuando se trate de derechos protegidos e, inversamente, a la norma o la interpretación más restringida, cuando se trate de establecer límites para su ejercicio (Tesis XXVII, 2014, p. 67).

c) Plan Nacional de Desarrollo

A lo antes enunciado, agregamos el contenido del Plan Nacional de Desarrollo, regulador de las acciones que debe seguir el Ejecutivo en turno, bajo este rubro, del cual se derivan las metas y estrategias que en la administración pública han de observarse para cumplir los objetivos planteados. La idea consiste en que la educación se desdoble como un pilar en México, a la par de otras actividades generadoras de riqueza y bienestar en el país: industria, minería y agro.

Atentos a este instrumento de trabajo, identificamos, en su eje III, el tratamiento que se hace sobre educación para la administración en turno.

Hemos de considerar que el plan comentado busca un rediseño de las instituciones públicas, en términos de Barroso, supra-, obedece a una reingeniería del Estado de derecho, en el sentido de ponderar sus acciones eslabonadas en atención a la persona; es decir, la teoría de la reingeniería constitucional - introducida primero en Brasil- México la adopta debido a la proyección que se otorga en áreas de gobierno, para promover sus actividades de cara a la persona. 
Como se dijo en el apartado que nos antecede, el Estado debe reconstruir sus áreas públicas, con base en el iusnaturalismo del siglo XVIII, para atribuir al ser humano el cúmulo de derechos y premisas que a este ente le corresponde garantizar y cumplir como parte de sus funciones públicas, ese que, al mismo tiempo, le permita justificar su existencia social.

En virtud de que el fundamento de los derechos humanos lo constituye la dignidad humana, pues por razón de su intrínseca naturaleza todo ser humano debe gozar de una serie de libertades y prerrogativas que le permitan vivir como tal y alcanzar su pleno desarrollo, la titularidad de los derechos humanos se extiende enteramente al género humano. Por ello, los Estados, con independencia de su sistema político, económico y social, deben reconocerlos, respetarlos, protegerlos y garantizarlos (Silva, 2014, p. 9).

Continuamos sobre este discernimiento doctrinal, en la postura que introduce nuestro plan vigente, para estimar un calificativo positivo, en buscar la renovación y redimensión de los actos públicos en pro de la persona.

Tal progreso administrativo fincado en la corriente iusnaturalista racional y en el principio pro persona, derivado del artículo $1 .^{\circ}$, se refleja en la misión señalada en el plan de gobierno vigente, bajo sus 5 ejes establecidos. La educación es incluida en esta planificación administrativa, dependiente del respaldo económico que se le otorgue en presupuesto anual, con fuente en contribuciones nacionales, en concordancia con otros instrumentos jurídico-económicos, los cuales consientan su financiación como derecho humano para México.

El ciudadano - por su parte-, a quien se destinan los aportes económicos y programas educativos, debe significar en positivo la remisión que hace el ente público de estas partidas, para atender las demandas educativas, en apego al texto constitucional.

Existe poca reciprocidad entre el sujeto beneficiado y la entidad emisora de las acciones educativas, debido a la escasa información de actos y programas. También influye el demérito de la función pública en causas diversas, como falta de transparencia, corrupción, representación sindical, capacitación de personal, burocracia, desfase entre política educativa y realidad, aportes económicos inequitativos, priorizar otras áreas como la política democrática.

A lo anterior agregamos la desatención a las condiciones actuales en educación, como aulas, pago de profesores, asignación de plazas, distribución de recursos humanos en zonas de adscripción, oportunidades de empleo, relación política 
entre sindicatos y la Secretaría de Educación Pública, vocación en el servicio, falta de trato humano al servidor de la educación, idoneidad en programas de estudio, entre otras.

El tópico como se advierte abre aristas que propician un trabajo integral a la luz del ser humano. En atención al objeto tratado en este trabajo, se aborda la educación como un derecho al servicio del ciudadano, en apego a los instrumentos jurídicos nacionales y extranjeros, así como a los tributarios que arrojan la financiación para ejercerlo, base para el mejoramiento y progreso de las generaciones tanto actuales como futuras.

Es decir, el Sistema Jurídico Mexicano se finca sobre imperativos inherentes al ser humano, en la categoría de derechos inmutables que con el paso del tiempo no puedan ser extinguidos, pero sí mejorar sus ámbitos de ejecución como pilares que sostienen el nacimiento del Estado Constitucional actual, en unión a las corrientes del pensamiento del siglo XVIII (Trejo, 2016, p. 219).

Enfocándonos en esta diversidad axiológica del Estado, vinculamos las finanzas públicas; en mandato constitucional, se justifica el cobro de contribuciones para satisfacer las necesidades colectivas. A ello remiten varios especialistas tributarios como Venegas (2016), quien apunta que "[...] la asignación de recursos públicos debe garantizar al menos la satisfacción de las necesidades públicas, regirse por el paradigma de la no discriminación y eliminar cualquier forma de arbitrariedad".

A continuación, retomamos los objetivos en el Plan Nacional de Desarrollo, con apego a sus metas y estrategias en materia de educación, concebida para nuestro estudio como un derecho humano o DESC.

Para el diagnóstico general del plan, la educación es vista como un capital humano, donde el sistema educativo se debe fortalecer en respuesta a los requerimientos de un mundo globalizado.

Igualmente, el Poder Ejecutivo (2014) menciona que se hace latente la eficiencia en este ámbito, por medio de un trabajo en equipo, el uso de nuevas tecnologías para la solución de problemas:

Posteriormente - en este mismo documento - la educación se identifica como Tercera meta nacional, para lograr un México con educación de calidad, que permita el desarrollo de todos los mexicanos, en la formación de estudiantes, en concomitancia a los planes de estudio, capacidades y habilidades que deben emplearse en el exterior; de esta forma se generará un servicio con valor agregado (Poder Ejecutivo, 2014, p. 22). 
Con relación a nuestro objeto de estudio, los Derechos Humanos aparecen bajo un tratamiento que engloba el compromiso de las autoridades en el país, para garantizar que las personas vivan en mejores estándares, con la menor violación a sus derechos y garantías, ello como parte del Diagnóstico y temática sobre Gobernabilidad Democrática en el Plan Nacional vigente, con mayor pronunciamiento de este ámbito en impartición de justicia (Poder Ejecutivo, 2014, p. 35).

En su contenido posterior, el plan denomina su tópico III: "México con educación de calidad". Identifica, en este, una política de educación - no obstante, su mención como directriz inicial del documento-, que busca el desarrollo del país referido a sus homólogos, vía la apropiación del conocimiento, que propenda en la población y aculturación para un México futuro, con estándares apuntalados en formación y profesionalización de los habitantes.

Como estado de la cuestión, en este orden de ideas, parafraseamos el instrumento de gobierno, rector de la política educativa, que establece las directrices de impartir la educación en el nivel nacional:

a) De acuerdo con una visión internacional, la ciencia y tecnología refieren el impulso para el cambio educativo, por medio de su inversión y aplicación al interior del país.

b) Por lo anterior, el presente plan pretende el impulso a la cultura y el deporte, a la par de la educación, en sus objetivos fundamentales —del 2013 al 2018-.

c) Tal documento muestra el diagnóstico en este ámbito, con datos cuantitativos, en estudiantes de nivel básico: de niños a jóvenes, en una distribución escolar de casi 228000 escuelas, sin incluir la educación superior.

d) Por otra parte, se hace latente la profesionalización de los docentes.

También, el Poder Ejecutivo (2014) precisa que "la impartición de la educación busca dar herramientas para satisfacer las necesidades económicas y sociales, a las que se enfrentan los jóvenes hoy en día" (pp. 32-33).

En comento al Plan Nacional de Desarrollo, su tópico VI.3: "México con educación de calidad", describe como líneas de acción estimular el desarrollo profesional y robustecer programas de formación. En este orden, enuncia como estrategia para lograr los objetivos educativos "la modernización de la infraestructura, garantizar planes y programas de estudio para una educación pertinente, promover la introducción de nuevas tecnologías y disminuir la deserción escolar" (Poder Ejecutivo, 2014, pp. 77.79) 
Como se observa, muchos son los retos a los que somete el documento de gobierno a los actores de la educación en México, en los niveles obligatorios de preescolar a media superior. Lo previo máxime en el proceso de su cumplimiento, que se encuentra a menos de un año de finalización con la Administración Pública Federal de la actualidad.

\section{a) Jurisprudencia}

Seguidos en el estudio que se aborda — atentos a la praxis jurídica-, agregamos la postura del máximo Tribunal Judicial, en cuanto a la suficiencia económica que el Estado asigna a los programas regionales por año. Esto, en razón de justificar los aportes presupuestales, que el Poder Ejecutivo y el Legislativo (como sujetos de la política fiscal) estimen pertinente destinar a sectores educativos, conforme a sus competencias - artículo 73, fracción VII y 71 constitucional- en la Carta Fundamental: establecer y destinar partidas que permitan ejercer la educación en aulas, en niveles educativos obligatorios. Destaca el ente jurisdiccional en mención los límites que el Poder Público fije, en la aprobación de las aportaciones económicas a este fin.

Existe una obligación del Estado de verificar la correcta aplicación de los recursos destinados para el cumplimiento del derecho humano a la educación, de la cual se advierte el carácter del Estado como sujeto obligado y comprometido a través de instrumentos internacionales (SCJN, 2015).

Enunciamos este criterio jurisprudencial, como elemento medular que conduzca a ratificar la obligación estatal en brindar educación, como un servicio y derecho humano condicionado a los límites establecidos por los actores públicos, en la asignación de presupuestos a las áreas de la administración. Ello considerándose que, al destinar recursos para este fin, se cumple con la responsabilidad constitucional expresa a cargo de los entes de gobierno, sin puntualizar la suficiencia en la asignación de las aportaciones fiscales orientadas al ramo educativo, ante la teleología de lograr la eficiencia en el servicio otorgado; satisfacer, por ende, la demanda del contexto social abordado.

Lo especificado, bajo la distribución de contribuciones al gasto público, en territorio subnacional y municipal.

Con lo anterior, anticipamos el cumplimiento inapropiado e insuficiente que el Ejecutivo pueda hacer en educación como derecho humano, bajo el reflector de una política fiscal sujeta y condicionada a los límites que le imprimen los entes mencionados, ante la concesión de presupuesto limitado, con transcendencia a 
los objetivos constitucionales y del plan (en la educación frente a la reingeniería estatal).

En ejercicio de competencias, los actores facultados no vinculan, en lo real, la asignación de partidas económicas. Justifican tal otorgamiento taxativo por criterio jurisprudencial, no obstante, la repercusión en las necesidades de los planos educativos obligatorios: en sus programas y planteles.

Estas ideas nos indican el paso a una indagación empírica que nos habilite el empleo de las estipulaciones fiscales por programa y región, de cara a la financiación que el Ejecutivo considere disponer, para un mejor acceso a la educación.

En relación con ejecutar la subvención en derechos humanos:

Los jueces aseguran la prevalencia de los derechos humanos contenidos en la Constitución y los tratados internacionales sobre cualquier disposición de carácter legal que sea contraria a esos derechos, dejando de aplicar esa norma al caso en concreto sin hacer declaratoria general sobre su invalidez (Pérez, 2014, p. 103).

Estimamos que las partidas económicas contempladas en el rubro educativo se someten a las condicionantes que el Ejecutivo y Legislativo les impongan, por conducto de los presupuestos anuales; ello sin corresponder a un incumplimiento al mandato constitucional: determinar las contribuciones para proveer el gasto público y satisfacer las necesidades en el país.

Tal estipulación presupuestal posee un carácter cualitativo, no incluye porcentajes que constitucionalmente fijen un mínimo o máximo, para destinar tributos a la educación anualmente. Por lo tanto, se deja en la competencia del Ejecutivo y su correlación con el Legislativo, imponer los diques a la financiación en esta esfera. Esto significa que la Constitución, al no señalar las bases presupuestales para su distribución en la administración pública, delega en los entes públicos aludidos la reserva correspondiente, por medio de la Ley de Ingresos y Egresos de cada año.

De acuerdo con nuestras ideas precedentes en identificar la competencia constitucional, en la asignación de gasto público a la educación, citamos al doctor Valadés (2001), quien aborda el tópico presupuestario en un derecho comparado, para identificar porcentajes establecidos en una prelación supralegal. 


\section{Tabla 3}

Tópicos presupuestarios en un derecho comparado

\begin{tabular}{|l|c|c|}
\hline \multicolumn{1}{|c|}{ PAÍS } & $\begin{array}{c}\text { ARTÍCULO } \\
\text { CONSTITUCIONAL }\end{array}$ & PORCENTAJE EN EDUCACIÓN \\
\hline Ecuador & 71 & $30 \%$ \\
\hline El Salvador & 61 & En presupuesto \\
\hline Guatemala & 84 & $5 \%$ \\
\hline Honduras & 161 & $6 \%$ \\
\hline Nicaragua & 125 & $\begin{array}{c}\text { Aporte para establecer y desarrollar } \\
\text { educación superior }\end{array}$ \\
\hline Panamá & 100 & \begin{tabular}{c}
$20 \%$ \\
\hline Paraguay
\end{tabular} \\
\hline Venezuela & 85 & $\begin{array}{c}\text { Prioridad en educación y desarrollo } \\
\text { científico }\end{array}$ \\
\hline
\end{tabular}

Nota. (Tabla: autora).

\section{Política fiscal para la educación en México}

Nos corresponde, acto seguido, abordar los elementos económicos que facultan conocer las partidas y la prelación normativa en el sistema tributario actual, las cuales coadyuven al financiamiento de la educación como derecho humano, de cara a las atribuciones de los entes habilitados para ello, así como el pronunciamiento que ha realizado la Corte Suprema en el país, en el afán de ratificar los límites producidos en las partidas presupuestales del ámbito federal.

En este último apartado de nuestra indagación, se incluye la política fiscal como acción del Gobierno que se encarga del estudio y precisión de contribuciones, para ser destinadas a programas sociales y mantener un equilibrio económico colectivo por la administración en turno. También se describen los montos presupuestales en el 2017, que amparan la realización educativa en la República Mexicana.

Siguiendo lo anterior, analizamos los principales instrumentos fiscales federales, en alcance a los objetivos del Plan Nacional de Desarrollo Económico vigente, que vincula al sistema tributario como sendero para fortalecer la política educativa.

La política fiscal, como instrumento del gobierno mexicano, desarrolla entre sus objetivos las contribuciones que han de ser introducidas en los textos fiscales, con destino a un presupuesto de egresos. 
Conforme a sus elementos, nos adherimos a la obtención de ingresos, erogación y técnica legislativa, elementos que instan su aplicación, vía las funciones que el Estado ejerce frente a los particulares.

Desde un punto de vista del federalismo fiscal, aquella (la política fiscal) interviene como una herramienta que agrupa a los sujetos financieros, tributarios, las remuneraciones por recaudarse y su ocupación en el gasto público.

Bajo estas anotaciones, el Estado mexicano se apoya en la política financiera y fiscal, para el cumplimiento de sus actividades, por medio de la génesis, gestión y aplicación de recursos al presupuesto de egresos.

Acotamos, en el orden descrito, nuestro objeto de estudio a los fines, objetivos y elementos de la política tributaria, en los ingresos ordinarios que el Estado percibe, a través de las obligaciones de pago de los contribuyentes.

Consideramos, también, en torno a la fuente de financiamiento empleada, con base en las aportaciones y participaciones - medios ordinarios económicos-, su asignación por conducto de instrumentos e instituciones del sistema fiscal, que promoverán la financiación en materia educativa como derecho humano.

Puntualizamos, en esta investigación, el uso de la teoría general de las contribuciones, como cimiento en la creación de los ingresos nacionales que el Estado percibe, con base en la recaudación de tributos que nacen al actualizar hechos imponibles.

Corresponde, entonces, al legislador fiscal y Ejecutivo nacional generar los mecanismos que den suficiencia económica a este derecho humano, por conducto de leyes administrativas y tributarias, reglamentos, decretos, estímulos, impuestos extrafiscales y parafiscales, a la par de la producción normativa emanada de delegados hacendarios; todo en cuanto a reglas de carácter general, circulares y demás actos aplicables como facultados del sistema tributario, enlazados al principio de legalidad y su apoderamiento social.

De acuerdo con lo planteado, enunciamos cómo se correlaciona, en esta indagación, un marco teórico y prelación normativa, que integre y conduzca a la determinación de objetivos cuantitativos, donde el Ejecutivo nacional contemple, para cada año, la educación - en cumplimiento a su clasificación en derecho social, cultural y económico-; como una tercera categoría de garantías, con fuente en el numeral $1 .^{\circ}$ constitucional, como derecho humano a partir del 2011.

Por lo tanto, el Estado mexicano, con la reforma en mención, abre una gama de funciones que dirigen a satisfacer este servicio público, con carácter obligatorio 
en sus niveles de preescolar a educación media superior, con fundamento en el artículo $3 .^{\circ}$ de nuestra carta magna.

La cuestión del control de las políticas públicas involucra, de manera igual, la demarcación del límite adecuado entre la materia constitucional y la materia a ser sometida al proceso político mayoritario. Por un lado, la Constitución protege a los derechos fundamentales y determina la adopción de políticas públicas para realizarlos: por otro, atribuye las decisiones sobre la inversión de recursos y las opciones políticas que se deben perseguir, en cada momento, por los poderes Legislativo y Ejecutivo (Barroso, 2008, p. 61).

A la sombra de este tenor, se aprecian los retos que la administración pública debe atender en pro de la persona humana, desde la óptica de sus garantías preestablecidas, en las que destacamos el acceso a la educación en el territorio mexicano.

Se requiere una planeación y programas que, por regiones, permitan el cumplimiento de estas premisas en beneficio de los receptores de la educación.

También expresamos la confrontación entre demanda y programación, teniendo en cuenta la población correspondiente a niveles educativos, obligados a recibir instrucción frente a una matrícula real.

Las partidas económicas destinadas anualmente, a priori, estimamos representan insuficiencia para solventar la demanda educativa por región a cada educando, sin ponderar la deserción escolar que se presenta por diversas causas en el país.

Como se advierte, el ramo administrativo en cuestión recibe cuantitativamente los aportes que por presupuesto le asignan en ejercicio fiscal. Coexisten focos por atender, de cara a una eficiencia del servicio educativo público, frente a las estipulaciones económicas que permiten su práctica en aulas, por programas de gobierno y áreas de investigación.

Para acotar con mayor precisión nuestro objeto de estudio, solo se mencionan (infra-) las partidas que correspondan a este ámbito administrativo, en la categoría de programa concurrente, que posibilite la coyuntura con otras dependencias de gobierno, en virtud de la educación; la persona como centro en las acciones y funciones de delegados facultados en el área.

Es decir, con base al párrafo anterior, agrupamos a los sujetos actores en instituciones que coadyuven a la investigación y programas educativos a la luz de a) créditos fiscales, b) estímulos o c) presupuesto asignado. En los incisos a) y b), referimos a contribuyentes que tributan o practican indagaciones en forma altruista al servicio 
de la educación; en el inciso c), identificamos dependencias de Gobierno que forman parte de su estructura federal o se beneficien con aportaciones anuales; tal es el caso de institutos, centros educativos y de investigación, la Secretaría titular de Educación Pública y el Consejo Nacional de Ciencia y Tecnología.

Seguidos en el enfoque administrativo, fiscal y presupuestario de la educación como derecho humano, puntualizamos los elementos que se interrelacionan en su estado de la cuestión. Se destaca el sistema tributario - con su uso en impuestos no recaudatorios y alternancia de pago-, entes que intervienen en la administración pública: sujeto pasivo, el administrado para recibir educación, el Ejecutivo nacional como rector de esa función, la Secretaría de Hacienda y Crédito Público, el Servicio de Administración Tributaria y la Secretaría de Educación Pública.

Sumamos a lo enunciado, las entidades públicas y privadas que contribuyen en educación, por su gestión altruista, las cuales se convierten en acreedoras de beneficios y estímulos vía decreto delegado.

El gobernante nacional encabeza los sujetos actores, encargados por constitución y ley, del ejercicio de tal función pública; se incluyen los aportes de la sociedad civil en este rubro. Existe correlación entre actores públicos y privados para este fin; los efectos de convenios internacionales significan que, en el plano supranacional, actúan en favor de la educación, como crecimiento de las sociedades.

Para el caso que nos ocupa, las fuentes externas que arrojan recomendaciones y estándares en el tratamiento de la educación, en nuestras regiones, son contempladas en leyes y normativa aplicable para innovación, en lo correlativo al mandato constitucional: ser norma suprema junto a la carta fundamental y demás órdenes del sistema jurídico mexicano. Lo anterior pone de manifiesto la relación del derecho interno y el externo, ante la incorporación de este en normas ordinarias.

Con estas ideas, para la investigación — que nos ocupa—, identificamos, en un estadio normativo, diversos ordenamientos que hacen viable el desarrollo de la educación como derecho humano, de cara a la financiación en categorías fiscales reguladas para esa finalidad: Constitución, Ley de Educación, reglamento, Ley del Servicio de Administración Tributaria, Ley Orgánica de la Administración Pública Federal, Ley de Egresos, Ley de Ingresos, Código Fiscal Federal y Ley del Impuesto Sobre la Renta con sus reglamentos, así como los decretos vigentes de este sexenio, en provecho de la educación. De tal bando normativo, nos apoyaremos, a continuación, en las de contenido tributario y financiero, para abordar las competencias de los entes de gobierno, al determinar la financiación 
que arrope el ejercicio de programas educativos, atentos al artículo $3 .{ }^{\circ}$ de nuestro texto constitucional mencionado.

\section{a) Presupuesto de Egresos 2017}

El tema de las finanzas públicas en la importancia intrínseca que poseen permite al Estado la programación, planeación y cumplimiento de acciones; «por medio de la obtención de ingresos ordinarios, reflejados en el Presupuesto de Ingresos y Egresos de cada año»; visto éste como el instrumento jurídico, social, político y económico que se integra por el pago de contribuciones que realizan los contribuyentes (Trejo, 2007, p. 284).

Ante la obligación estatal de atender las necesidades sociales, los recursos económicos cobran importancia para la realización de programas educativos. En tal virtud, las partidas del Presupuesto de Egresos aprobado para el 2017 permiten el estudio al financiamiento de la educación como derecho humano.

Así, encontramos las remuneraciones bajo el ramo 11, en el Presupuesto de Egresos Federal (2016) que pondera a la educación pública bajo los aportes económicos de hasta “\$3, 856,542,571”, en el anexo 7 .

El anexo 10, de este mismo presupuesto federal (2016), remite a erogaciones para el desarrollo integral de los pueblos indígenas; el ramo 11 da financiamiento a labores en esta finalidad. Se regulan 7 programas destinados a esta particularidad, bajo un total de “\$9, 653,643,268” (p. 52).

El anexo 11, agrupa subprogramas como parte del Programa Especial Concurrente en el Desarrollo Rural Sustentable; la educación pública recibe aportes económicos en "\$30,959.1”. Al Programa de Educación e Investigación, en este contorno transversal, se le asignaron “ $\$ 36,896.1 ”$ (p. 53).

En el anexo 12 se regula la financiación al Programa de Ciencia, Tecnología e Innovación; el ramo 11 relativo a educación pública concede partidas por “\$26,818,783,982” (p. 54).

Más adelante, en el anexo 13, se establecen erogaciones para la igualdad entre mujeres y hombres; se atribuyen a educación pública aportaciones para 7 programas, en un monto de “\$3,764,977,008” (p. 54).

Con el anexo 14, se destinan recursos para la atención de grupos vulnerables; el ramo 11 de educación pública respalda, en este campo, 3 Programas Nacionales 
y apoyo tanto a los centros como a organizaciones de educación, en aportes por “\$1,392,618,545” (p. 54).

Las partidas que soporta el anexo 16 se destinan a la adaptación y mitigación del cambio climático; el ramo 11 recibe remuneraciones para educación superior y el Programa de Becas, en un valor de “\$60,472,988” (p. 54).

En la distribución de los ingresos ordinarios, el anexo 17 se denuncia las estipulaciones para el desarrollo de los jóvenes, a la luz de la educación pública, bajo 29 rubros o programas, arropados económicamente y distribuidos en educación básica: " $\$ 15,633,200,296$ ", educación media superior: " $\$ 78,413,539,947$ ", educación superior: “ $\$ 109,804,526,627$ ” y posgrado: “ $\$ 1,895,634,856 ”$ (p. 55).

Estos aportes suman, en total, $\$ 205,745,901,625$ pesos mexicanos, emanados de presupuesto federal.

Para el apoyo de las entidades federativas y municipios, se otorga bajo el ramo 33 aportaciones en materia de educación básica, educación media superior y educación superior, un monto de “ $\$ 12,540,795,762$ ” por ejercerse en 9 programas (p. 58).

El anexo 18, para la atención de niños, niñas y adolescentes en materia de educación pública, destina partidas económicas por " $\$ 126,441,975,932$ ”, para atender subprogramas en el país, en 24 secciones, en tópicos como política educativa, cultura, deporte, becas, estudio de inglés y desarrollo profesional (p. 59).

Para los sistemas básicos, se regulan remuneraciones bajo el contenido del anexo 25 , en 3 categorías: normal, tecnológico y adultos, en tributos que reúnen “\$37,367,286,540” (p. 59).

En el Presupuesto de Egresos Federal (2016), se designan fondos nacionales para estados y municipios en 10 tipos, para fortalecer los programas enunciados en anexos precedentes, los cuales mencionamos seguidamente (p. 59).

En correlación con los objetivos coyunturales del Plan de Desarrollo, el Presupuesto de Egresos de la Federación (2016), en su anexo 19, ocupa partidas para la prevención del delito, combate las adicciones y la promoción de proyectos productivos, por conducto del ramo 11 de educación pública, en 11 programas que atienden: deporte, desarrollo cultural, becas, convivencia escolar; bajo una estipulación de “\$73,432,848,802” (p. 60). 
Los anexos que se han relacionado exponen la financiación que el Ejecutivo federal designa a educación como derecho humano, para su repartición en programas regionales, estatales y municipales.

Se destaca el anexo 11, por consagrar el programa especial concurrente como soporte de los objetivos del plan de gobierno en vigor, en fortalecer, desde diversos ángulos, la educación pública y, en forma recíproca, los ámbitos receptores, que comprenden una aplicación en niños, jóvenes, adultos, población indígena, área tecnológica, investigación, tecnología y demás sectores señalados. Estos son atendidos bajo la corresponsabilidad que la administración pública busca.

En otras palabras, los ámbitos que acogen la educación pública por medio de este Programa Concurrente también se benefician a la luz de la política educativa, en razón de cómo se incorporan al Presupuesto de Egresos 2017.

Se da paso, de esta manera, a la reingeniería estatal, que pondera a la persona como centro de sus actividades; emplea recursos tributarios en materia de educación pública y otras áreas de gobierno, para fortalecer la transversalidad de la administración actual.

Pasamos, acto seguido, al análisis de ordenamientos hacendarios, que tipifican los estímulos y demás acciones de la política fiscal en coadyuvancia a la educativa.

\section{b) Leyes Fiscales \\ 1. Código Fiscal}

El Código Fiscal Federal, en sus artículos 25 y 25-A, establece los estímulos que puedan ser accedidos por las personas obligadas al pago de contribuciones, ante la alternancia de este compromiso, frente a la promoción y mejora en áreas sociales; tal es el caso de la educación que pueda ser abrazada con estos beneficios tributarios (CFF, 2016).

Es importante mencionar que los estímulos que el legislador fiscal pueda autorizar cualitativamente, en este ordenamiento hacendario, también sean extendidos al espacio educativo en sujetos actores de carácter independiente, que, frente al pago de tributos como renta e impuesto al valor agregado (IVA), puedan optar por aquellos, ante una baja recaudación o exención de pago en sus adeudos hacendarios.

En otras palabras, los pagadores del impuesto que brindan servicios de educación - como los catedráticos y profesores - pueden verse atenuados en el pago del IVA, más que todo, al ser clasificados prioritariamente en el régimen de asalariados 
o asimilados a salarios, fuera del régimen de ocupación independiente, como se encuentran regulados.

La obligación y el deber tributario en sujetos de régimen autónomo, a la hora de impartir educación, son distintos a lo que poseen las entidades delegadas por el Estado, como dependencias educativas. Esto se debe a que solo trasladan los montos retenidos por ISR y determinan la base para el pago del impuesto al valor agregado; son gestoras o retenedoras, exentas en este último tributo.

Por lo tanto, existe una desigualdad de trato frente al profesional libre y personas morales, quienes, sin tener ánimo de lucro, se benefician con esta prestación institucional delegable.

\section{Impuesto sobre la renta}

En el pago del impuesto sobre la renta, las personas físicas que tributan por ingresos derivados de la educación tendrán dos regímenes específicos. El primero corresponde a la persona asalariada que goza de todos los beneficios y prerrogativas laborales: salario fijo, días de descanso, antigüedad, prima vacacional, incremento de salario, reconocimiento de antigüedad y jubilación. Ello obedece a los niveles educativos básico, medio, medio superior y superior, con independencia de los patrones y fuentes económicas que permitan el cumplimiento de estos mínimos laborales.

Para este grupo asalariado, cuando recibe estímulos fiscales, su finalidad será brindarles baja recaudación o exentarlos en el pago de obligaciones hacendarias; por ejemplo, la determinación del Ejecutivo federal, cuyo contenido se difunde con el comunicado del Servicio de Administración Tributaria, el cual exime de la declaración anual a las personas físicas, con un solo patrón, que no hayan excedido el límite anual de ingresos (500,00 aproximadamente), para no presentar su declaración anual del ejercicio inmediato anterior (año 2016), en el ejercicio fiscal 2017, y solicitar las devoluciones que les puedan corresponder.

Sin embargo, estos beneficios solo comprenden la capacidad económica del contribuyente, sin trascender a la esfera educativa como contraparte, en capacitación, aprendizaje de idiomas o lengua indígena, formación en medios digitales, mejora del proceso enseñanza-aprendizaje, etc.

Tales apoyos fiscales, que eximen de la declaración anual al contribuyente en medio educativo, solo atienden los fines recaudatorios del sistema tributario y no los objetivos de los impuestos parafiscales; en baja recaudación o exención de pago, promover y progresar recintos específicos sociales. 
Por lo dicho, no existe correlación del sistema tributario con impuestos no recaudatorios, frente a la política educativa, como cumplimiento a los fines coyunturales del Plan Nacional de Desarrollo, que busca afinidad entre sus políticas públicas.

En el segundo caso (régimen), los trabajadores independientes no gozan de las prestaciones enunciadas en el primero. En tal virtud, el Estado debe atender mayormente al sector que labora bajo contrato y obra determinada; esos trabajadores no cuentan con una relación laboral estable, que haga posible una planeación individual o familiar de vida como servidores de la educación, al tenor de circunstancias que les propicien acato a los derechos humanos.

Se trata, entonces, de ampliar la visión del principio pro persona en el terreno educativo, que comprende, en primer momento, al educando y la profesionalización de los docentes con plaza; se deja en un extremo a los miles de servidores independientes quienes, junto al Estado, hacen posibles los retos de la educación en los distintos niveles.

Desde esta óptica, los derechos humanos también se deben incluir en la educación para sujetos tributarios, que permiten el cumplimiento de programas federales, estatales y municipales.

La Ley del Impuesto Sobre la Renta, LISR (2016), en su título IV relativo a personas físicas, capítulo I, establece la obligación de tributar para estos prestadores de empleo, por salarios o servicio personal subordinado - artículos del 94 al 99- (pp. 168-176).

\section{Ley del Impuesto al Valor Agregado}

Reiteramos al segundo caso (supra- en ISR), trabajadores independientes, que prestan servicios vía contrato o producto determinado; persona física que tributa en términos de la Ley del Valor Agregado, puede tener distintos patrones, sin una relación laboral que le otorgue prestaciones como trabajador asalariado.

Dicha ley, entre las actividades que grava el capítulo III relativo a prestación de servicios, artículos del 14 al 18-A, LIVA (2016), precisa las obligaciones de los contribuyentes que brindan educación en régimen independiente, ante la obligación genérica de pago en forma mensual y con recibos de honorarios. Se establece la exención a tal deber, en el artículo 15, cuando estos servicios sean gratuitos o se esté en la fracción IV (pp. 29-36), que identifica impartir educación como exenta, a la letra siguiente: 
Artículo 15, EXENCIONES TRATANDOSE DE PRESTACIONES DE SER-

VICIOS, no se pagará el impuesto por la prestación de los siguientes servicios:

\section{Los servicios de enseñanza}

IV. Los de enseñanza que preste la Federación, el Distrito Federal, los Estados, los Municipios y sus organismos descentralizados, y los establecimientos de particulares que tengan autorización o reconocimiento de validez oficial de estudios, en los términos de la Ley General de Educación, así como los servicios educativos de nivel preescolar (LIVA, 2016, p. 30).

Con la cita anterior, se advierte una política fiscal que coadyuva a la enseñanza por medio de un servicio, en pro de las instituciones oficiales o delegadas por el Estado.

Comprobamos, de este modo, lo establecido en líneas preliminares, cuando hablamos de los beneficios que los estímulos fiscales arrojan, por conducto de leyes tributarias, a la persona moral autorizada para ofrecer educación; no así, para el núcleo de profesores con relación personal independiente - como actividad empresarial- obligados por Ley del Impuesto al Valor Agregado.

En este orden de ideas, el sistema tributario remite a impuestos extrafiscales, con base en la exención hecha a estos sujetos, que suministran educación, ante su finalidad de atenuar o eliminar el pago de impuestos, cuando se dé la atención a un segmento social para su conservación o progreso.

Es innegable que los derechos humanos constituyen una pieza fundamental del correcto funcionamiento y la legitimidad del Estado de derecho, ya que hay una interdependencia genética: el estado de derecho no hubiera surgido sin la lucha por los derechos humanos y por su reconocimiento en las primeras declaraciones de los siglos XVII y XVIII; y los derechos no hubieran pasado de ser entidades morales o metafísicas, si el ordenamiento jurídico del Estado no los reconociera (Pérez, 2014, p. 114).

\section{Conclusiones}

Relacionado con la temática que se aborda, podemos expresar que la financiación consagrada en materia de educación como un derecho humano cumple los objetivos del Plan Nacional para el 2017, con vista en las partidas económicas que se dedican a este rubro, contenidas en los anexos expuestos, con particularidad el número 11 que contempla el Programa Especial Concurrente. 
La educación - como se observa- muestra acogida en los programas que han sido aprobados y solventados, a través de partidas fincadas en contribuciones federales, en símil a ingresos ordinarios para el 2017. Sobre su concepción como derecho humano a la luz del artículo $3 .^{\circ}$, párrafo segundo, hemos de considerar que su ejercicio con valores y ética corresponderá al beneficio en los ciudadanos.

De este modo, el tratamiento que se reconoce a la educación en el texto constitucional es dual: por una parte, se diseña en el capítulo $1 .^{\circ}$ como un derecho humano; por otra, en el numeral $3 .^{\circ}$ aludido, es un derecho de la persona que opera como instrumento o garantía para el cumplimiento de los derechos humanos.

Por lo tanto, los derechos humanos en materia de educación serán todos los procedimientos, normas y procesos que conduzcan a la persona a una instrucción y acceso, sin vulneración o exclusión.

La Constitución, como sistema normativo que tiene fuerza obligatoria y vinculante, se convierte en la positivación jurídica de los «valores fundamentales» del orden de la vida en común o en la condensación de unos principios de justicia suprapositivos. La ley, a su vez, queda vinculada a una instancia jurídica superior, como es la Constitución, lo que supone un redimensionamiento del principio de legalidad con validez material (Pérez, 2014, p. 115).

Las normas tributarias en su función elemental de la política fiscal participan en la recaudación de impuestos, por ingresos en servicios educativos (regla general).

Como particularidad, el Poder Legislativo y el Ejecutivo participan en la emisión de estímulos fiscales, contemplados en el orden normativo o decretos, respectivamente, para disminuir o alternar las cargas fiscales de los obligados tributarios, ante la preservación y el incremento del recinto educacional, en servicios altruistas.

Sin el ánimo de contradecirnos con lo dicho en líneas iniciales de este epílogo, al reconocer el financiamiento a la educación, de cara al Plan de Desarrollo y al presupuesto otorgado en el periodo 2017, no existen beneficios a la política educativa en subvenciones fiscales para persona física independiente.

Los impuestos extrafiscales aplican en materia de impuesto sobre la renta; las instituciones que brinden educación son eximidas en el pago de aquel, así como en el impuesto al valor agregado, sin extensión al aplicador autónomo de la educación. 


\section{Referencias}

Barragán, J. (1996). Sobre el régimen constitucional de la educación. México: Crónica legislativa.

Barroso, L. (2008). El Neoconstitucionalismo y la Constitucionalización del Derecho. México: UNAM.

Bidart, G. (1995). El derecho de la Constitución y su fuerza normativa en V. Carranca, Reforma Constitucional en Materia de Derechos Humanos. México: Suprema Corte.

Böckenförde, E. (2000). Estudios sobre el Estado de Derecho y la democracia en V. Carranca, Reforma constitucional en materia de Derechos Humanos. México: Suprema Corte.

Comité Nacional de Educación en Derechos Humanos. (2008). Plan Nacional de Educación

en Derechos Humanos de Brasil, Secretaría Especial de Derechos Humanos-Presidencia de la República. UNESCO.

Gutiérrez, G., Lujambio, A. y Valdés, D. (2001). El proceso presupuestario y las relaciones entre los órganos del poder. México: UNAM.

Congreso de la Unión. (2016). Presupuesto de Egresos Federal 2017. México: SEGOB.

Lechuga, S. (2016). Código Fiscal de la Federación. México: ISEF.

Lechuga, S. (2016). Impuesto al Valor Agregado. México: ISEF.

Lechuga, S. (2016). Impuesto Sobre la Renta. México: ISEF.

Pérez C. (2014). Retos y Obstáculos en la implementación de la reforma Constitucional en V. Carranca, Reforma Constitucional en Materia de Derechos Humanos. México: Suprema Corte.

Poder Ejecutivo. (2014). Plan Nacional de Desarrollo 2013-2018. México: SEGOB.

Sales, R. (2014). Desaplicación Administrativa de un Precepto Legal Notoriamente Inconvencional: un ejemplo en C. Pérez, Retos y Obstáculos en la implementación de la reforma constitucional en materia de derechos humanos. México: Suprema Corte.

SEGOB. (2016). Constitución Política de los Estados Unidos Mexicanos. México: Gallardo.

Silva, J. (2014). Derechos Humanos Parte General, Serie de Derechos Humanos. México: Color. 
Suprema Corte de la Justicia de la Nación. (2014). Derechos Humanos Parte general, Serie de Derechos Humanos. México: SCJN.

Suprema Corte de la Justicia de la Nación, Primera sala, (18 de mayo de 2015). Amparo en revisión 323/2014.

Suprema Corte de la Justicia de la Nación, Tribunales Colegiados de Circuito, (octubre de 2004). Amparo en revisión 799/2003.

Suprema Corte de la Justicia de la Nación, Tribunales Colegiados de Circuito, (febrero de 2005). Amparo directo 202/2004.

Tesis XXVII. $1^{\circ}$. (VIII Región) J/1 (10. a). (2014). Derechos Humanos Parte General, Serie de Derechos Humanos. México: Color.

Trejo, Y. (2006). Política Fiscal y Económica: Sus implicaciones en el Sistema Tributario

Mexicano. Cultura de Veracruz.

Trejo, Y. (2007). Enseñanza de la justicia fiscal en los planes de estudio de la licenciatura. En Letras Jurídicas. México: Universidad Veracruzana.

Trejo, Y. (2016). Los Derechos Humanos del Contribuyente en el Sistema Tributario actual. En La investigación e innovación para la mejora social. México: CENID.

Venegas, S. (2016). Derecho Fiscal parte general e impuestos federales. Oxford.

Zippelius, R. (1985). Teoría general del Estado. Ciencia de la política. UAL. 
